\title{
Study the Effect of Inductor and Pole Geometry on the Surface Roughness and Material Removal Weight Using Magnetic Abrasive Finishing Method
}

\author{
Basma Luay Mahdi ${ }^{1}$, Ali H. Kadhum ${ }^{2 *}$
}

\begin{abstract}
Author's affiliations:

1) Al-Khwarizmi College of

The traditional finishing method cannot keep up with recent labor Engineering, University of Baghdad, Iraq. market requirements, solve the problem of increasing production, improve basma.1@kecbu.uobaghdad.ed u.iq

2*) Al-Khwarizmi College of cost.

Engineering, University of Baghdad, Iraq.

kadhumali59@yahoo.com

Paper History:

Received: $18^{\text {th }}$ July 2020

Revised: $3^{\text {rd }}$ Dec. 2020

Accepted: $23^{\text {rd }}$ Jan. 2021

the surface roughness and accuracy of workpiece. While the unconventional magnetic abrasive finishing (MAF) method has shown as a promising technique that can be used to finish complicated surfaces. MAF finishes metals, alloy, ceramic, and other materials that are difficult to finish by other processes. In another word, MAF improves the quality of surfaces with low f

This paper focuses on optimize and study the effect of inductor and pole geometry (radius of hole, angle of core, angle of pole, radius of pole), on (surface roughness $(\mathrm{Ra})$ and material removal weight $(\mathrm{W})$ ) and fined the optimum values that increase the efficiency of MAF method. Taguchi method employed to study the influence of geometry parameters and find the optimum values using orthogonal array L9. The results conclude that the most significant factor that effects change in surface roughness $(\Delta \mathrm{Ra})$ and material removal weight $(\Delta \mathrm{W})$ are radius of the hole $(\mathrm{R})$ and angle of core $(\alpha)$, respectively.

Keywords: Magnetic Abrasive Finishing, Surface Roughness, Material Removal Rate, Geometry of Inductor and Pole.
\end{abstract}

\section{Introduction:}

Magnetic abrasive finishing is a new finishing technique, used for polishing flat, cylindrical, and other complicated internal and external shapes that are difficult to polish by using a conventional machining process. Magnetic abrasive finishing removes microchips and enhance the quality of the surface[1]. MAF was initially developed as a machining process in the US in the 1930s, who have the first patent there [2]. In the MAF process, the magnetic field controls and manages the cutting force. Thus, finishing pressure is applied electromagnetically that have produced a magnetic field [3]. The cutting tool significantly affects the quality and accuracy of finishing processes. In the MAF process, the magnetic abrasive powder (MAP) plays the role of the cutting tool. MAP occupies the working gap between the pole and the workpiece. Accordingly, magnetic flux density passes through the coil to create a magnetic field which magnetized MAP and formulates a magnetic abrasive flexible brush (MAFB), MAFB acting as a multipoint cutting tool. MAP gains an energy from the magnetic field, this gained energy is used to generate cutting and finishing forces to process the surface of machined parts. The workpiece is also magnetized. The magnetic force acts between the workpiece and the brush to finish it. The MAF process removes a very small amount of material by indentation and rotation of magnetic abrasive particles in the circular tracks $[4,5]$. The principle of the MAF method is a ferromagnetic abrasive powder densified by magnetic field energy which acts as a surface finishing brush, as shown in Figure (1.

The development of MAF in various materials and shapes was a concerning issue for researchers. Yang et al. [6], implements an optimizing for MAF using Taguchi's parameter design, on AISI304 stainless steel. They analyze the magnetic field characteristics for three different poles designs solid cylindrical pole, hollow pole, and hollow cylindrical grooved pole. Among these designs the hollow cylindrical grooved pole shows a better surface roughness quality. In terms of parameters influence, the magnetic field, pole rotational speed, feed rate, working gap, abrasive, and lubrication are the effective parameters relating to the process. Their results showed that the MAF technique leads to considerable surface quality. Deepak et al. [7], to reach a higher surface quality (likemirror surfaces) by improving MRR and Ra using stainless steel SS-409 as a workpiece. In this paper, it showed that MAF achieves a higher surface quality than the conventional finishing processes like lapping,

NJES is an open access Journal with ISSN 2521-9154 and eISSN 2521-9162

This work is licensed under a Creative Commons Attribution-NonCommercial 4.0 International License 
honing, etc. Yamaguchi et al. [8], an attempt to maintain the property of surface while enhance $\mathrm{Ra}$ with minimum MRR. The most important parameter in this work is the magnetic abrasive particles (brush). The results show an improvement in Ra by (50-60\%) and tool life by $(150 \%)$.

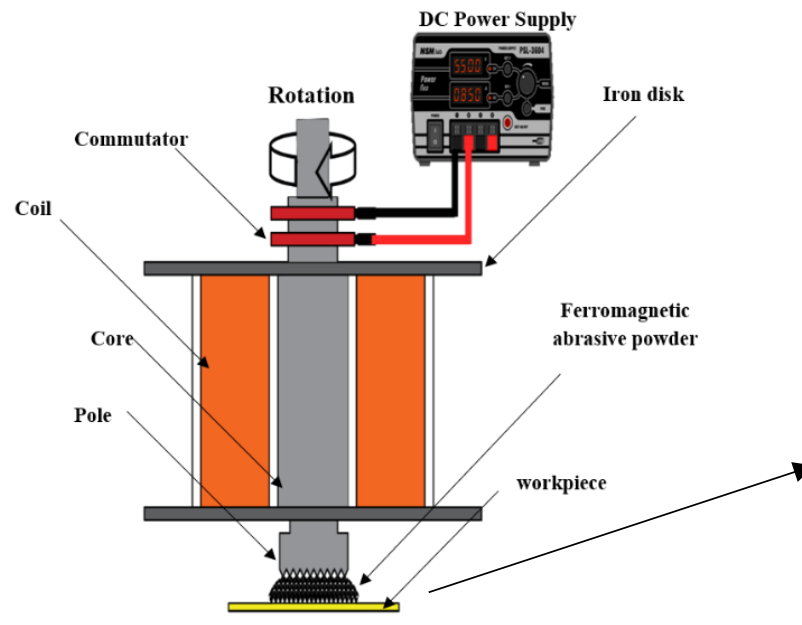

(a)

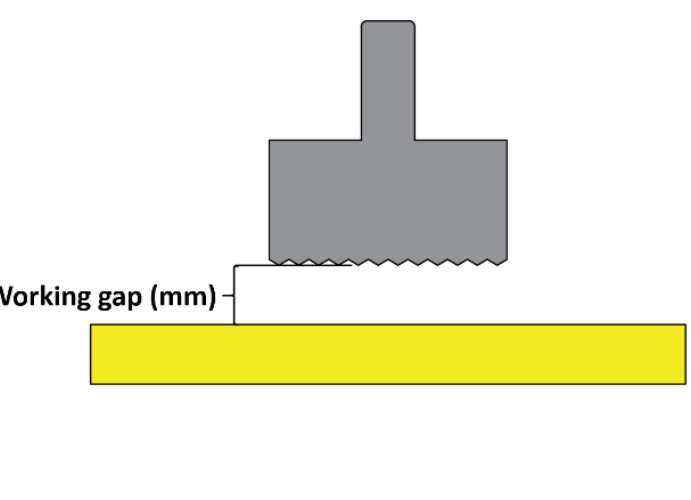

(b)

Figure (1): Principle of MAF process. Where working gap is the space between the tool and the workpiece

Mousa [9], study the optimization and influence of parameters (amplitude of pole geometry, number of cycles of pole geometry, working gap, finishing time, cutting speed, and current) on the quality of the surface of MAF for stainless steel 316 workpiece. They Utilize Taguchi method for finding the prediction models using the signal-to-noise ratio with the MINITAB 17 software. The results show that the surface roughness was decreased from $1.030 \mu \mathrm{m}$ to $0.370 \mu \mathrm{m}$, that means a higher level of surface roughness reached to $0.760 \mu \mathrm{m}$. The effect of the main process parameters (rotational speed of magnet, working gap, and mixing ratio) was considered on surface roughness $(\mathrm{Ra})$ during the finishing for the flat surface of Inconel 718 alloy. aimed to find the optimum process parameter that achieves minimum surface roughness value of Inconel 718 workpiece. The effect of this parameter on $\Delta \mathrm{R}$ a has been studied using L9 orthogonal array and analysis of variance ANOVA, it concludes that the minimum surface roughness achieved up to 0.0316 microns. While, the current and working gap is the most significant process parameters [10]. Furthermore, an attempt focused on developing the of finishing tool by using multiple poletip to achieve a higher $\mathrm{Ra}$, their results shown 94\% improvement in Ra with higher surface quality [11].

Besides, many researchers utilize the MAF process for polishing the external and internal surfaces. The external sphere surface such as (ball-bearing) made from AISI 316L stainless steel that has been polishing by the MAF process. It has input parameters are (electromagnetic speed, current and the direct voltage induced, magnetic flux density, the quantity of abrasive particle size, working environment, and workpieces materials), and the output criteria are (material removal rate and surface roughness). It concludes that the best surface finish $(\mathrm{Ra})$ can be obtained with $0.0766 \mu \mathrm{m}$ value at the optimal finishing conditions. By using the $\mathrm{S} / \mathrm{N}$ ratio and ANOVA analysis [12]. The MAF process is also effective on the internal surface such as aluminum pipes, by using adhesive magnetic abrasive particulate. The input parameters used in this process are (magnetic flux density, speed, abrasive grit size, and quantity of MAPs). The output characteristics are roughness improvement rate (RIR) and material removal rate (MRR), where Response Surface Methodology (RSM) method was utilized for analyzing. It concludes that the maximum value of RIR and MRR that can be achieved at the optimum condition are $(81.49 \%, 2.74 \mathrm{mg} / \mathrm{min})$, respectively [13].

Yet, measuring the impact of system geometry of inductors (pole and core) in the MAF system is still an open topic. In this paper, the optimum system geometry that achieves the best quality of surfaces according to the selected criteria (surface roughness and material removal weight) was set.

The objective of this paper is to study the effect of varying the MAF system geometry on the physical properties of the finished surfaces. Taking into consideration two criteria: surface roughness, and material removal weight, for Optimizing and improving the quality and the properties of flat surface (brass workpiece material) by using Minitab software program that found the best geometry for magnetic inductor. Taguchi orthogonal array $(\mathrm{OA})$ were utilized to design the experiments and to find the prediction model for each criterion. According to the criteria's response of changes in surface quality, Taguchi recommends two routes for analyzing and optimizing results: signal-to-noise ratio (SNR)and analysis of the variance (ANOVA) using Minitab 18 software.

Describe the overall procedure steps of MAF for the nine experiments as shown in Figure 2. 


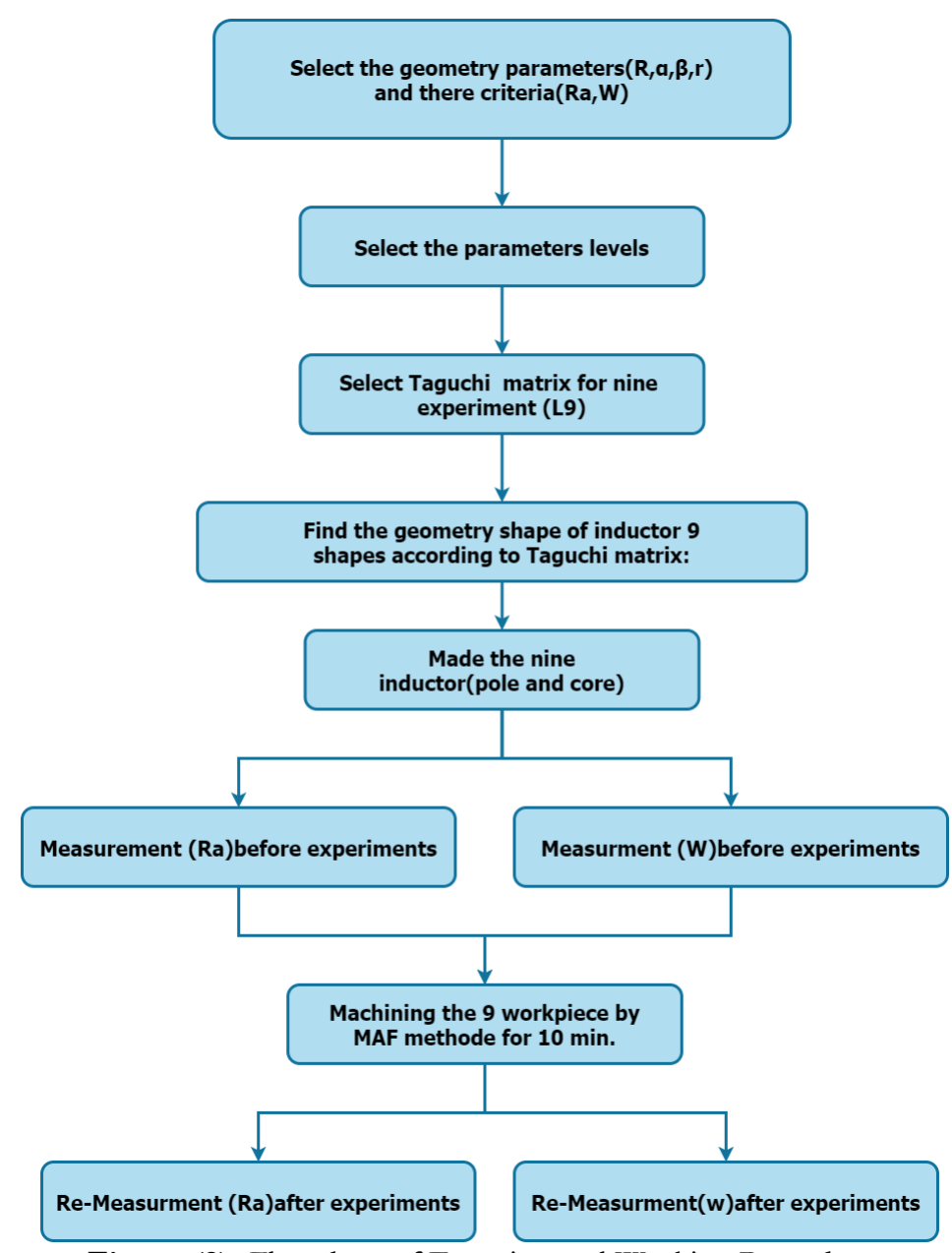

Figure (2): Flowchart of Experimental Working Procedure.

\subsection{Selection the levels and their parameter of} MAF

The objective of this work is studying the influence of magnetic inductor and pole geometry on the selected criteria ( $\mathrm{Ra}, \mathrm{W})$. To formulate the problem, four input variable parameters have been chosen (radius of hole $(\mathrm{R} \mathrm{mm})$, angle of core $(\alpha \mathrm{deg})$, inner radius of the pole $(\beta \mathrm{mm})$ and angle of the pole $(\mathrm{r} \mathrm{deg}))$. While fixing the remaining parameters (electric source, magnetic inductor velocity $(\mathrm{m} / \mathrm{s})$, finishing time (min), working gap ( $\mathrm{mm})$, and ferromagnetic abrasive powder doze (cc)). The ferromagnetic abrasive powder is a mixture of $50 \mathrm{~g}$ of Tungsten Carbide and $100 \mathrm{~g}$ of free Iron (ratio: 2 Iron to 1 Tungsten Carbide), with mesh $(320 \mu \mathrm{m})$. Measuring the effect of the input variable parameters on surface roughness and material removal rate in the magnetic abrasive finishing process. The values and levels of input parameters (variable parameters) and the values of constant variables are listed in Table (1): The values and levels of input (variable) parameters.

and

Table (2): The values of constant variables.

, respectively. The geometry parameters of electromagnetic inductor and pole and their dimensions are shown in Figure.
Table (1): The values and levels of input (variable) parameters.

\begin{tabular}{|c|c|c|c|c|}
\hline Input parameters & code & Level1 & Level2 & Level3 \\
\hline Radius of hole (mm) & $\mathrm{R}$ & 0 & 4.5 & 9 \\
\hline Angle of core (degree) & $\alpha$ & $82^{\circ}$ & $90^{\circ}$ & $98^{\circ}$ \\
\hline Angle of pole (degree) & $\beta$ & $60^{\circ}$ & $90^{\circ}$ & $120^{\circ}$ \\
\hline Radius of pole (mm) & $\mathrm{r}$ & -18 & 0 & 18 \\
\hline
\end{tabular}

Table (2): The values of constant variables.

\begin{tabular}{|c|c|c|}
\hline No. & Constant parameters & Value \\
\hline 1 & Electric source current (A) & 0.85 \\
\hline 2 & Electric source voltage (V) & 55 \\
\hline 3 & Magnetic inductor velocity (m/s) & 550 \\
\hline 4 & Finishing time (min) & 10 \\
\hline 5 & Working gap (mm) & 1.5 \\
\hline 6 & $\begin{array}{c}\text { Doze of ferromagnetic abrasive powder } \\
\text { (cc) }\end{array}$ & 10 \\
\hline
\end{tabular}




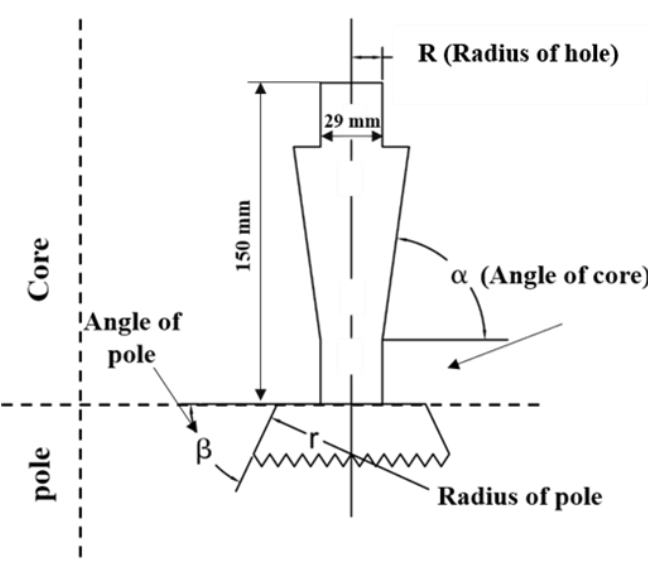

Figure (3): The parameters of electromagnetic inductor and pole.

\subsection{Selection of orthogonal array (OA) for nine experiments.}

The input parameters have been applied to a set of experiments according to an orthogonal array (OA). Orthogonal array is a technique that minimizes the number of experiments by taking the most effective experiments. An array of L9 $\left(3^{\wedge} 4\right)$ gives (81) independent experiments. Utilizing $\mathrm{OA}$ reduces the number to only (9) experiments[6], [14]-[16].

Table (3): The experimental design of magnetic inductor based on L9.

\begin{tabular}{|c|c|c|c|c|}
\hline Experiment & $(\mathrm{R})$ & $(\alpha)$ & $(\beta)$ & $(\mathrm{r})$ \\
\hline 1 & 0 & 82 & 60 & -18 \\
\hline 2 & 0 & 90 & 90 & 0 \\
\hline 3 & 0 & 98 & 120 & 18 \\
\hline
\end{tabular}
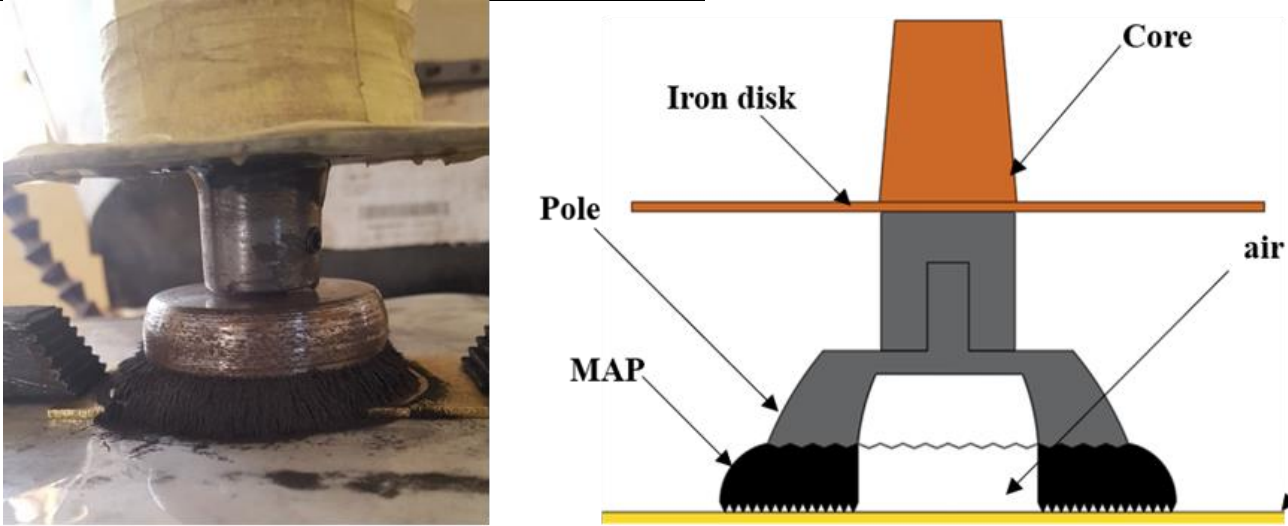

Figure (4): Brush formed in MAF process, a) Photograph b) Drawing

Table (4): Shapes of inductor and pole.
According to Taguchi technique matrix, nine are proposed shape for inductor and pole geometry, as shown in Error! Reference source not found.

After the fabrication of core and pole according to the scheduled shapes from the Taguchi array, the turning process started. With a copper wire of $0.5 \mathrm{~mm}$ diameter, in which each core is covered by (5000 turns) to form an inductor. The finishing process was confined to brass plates as workpiece. It has dimensions of $100 \mathrm{~mm}$ length with $50 \mathrm{~mm}$ width and $3 \mathrm{~mm}$ thickness. Figure 4 depicts the magnetic abrasive brush that begins to form after the electric current passed through the inductor. One of the most important factors that affect the shape of the brush is the geometry dimensions of the magnetic inductor and pole.

The magnetic abrasive finishing machine is illustrated in Figure 5. The criteria that affected by a change in surface characteristics are surface roughness (Ra) and material removal weight (W). Inside the machining zone, three fixed points 1,2, and 3 as shown in Figure 6, were selected as test points and measured for each experiment individually, before calculating the average. Then, the results before and after machining are been subtracted to find the change in $(\Delta \mathrm{Ra}$ and $\Delta \mathrm{W})$. 
NJES24(1)16-25, 2021

\section{Mahdi \& Kadhum}

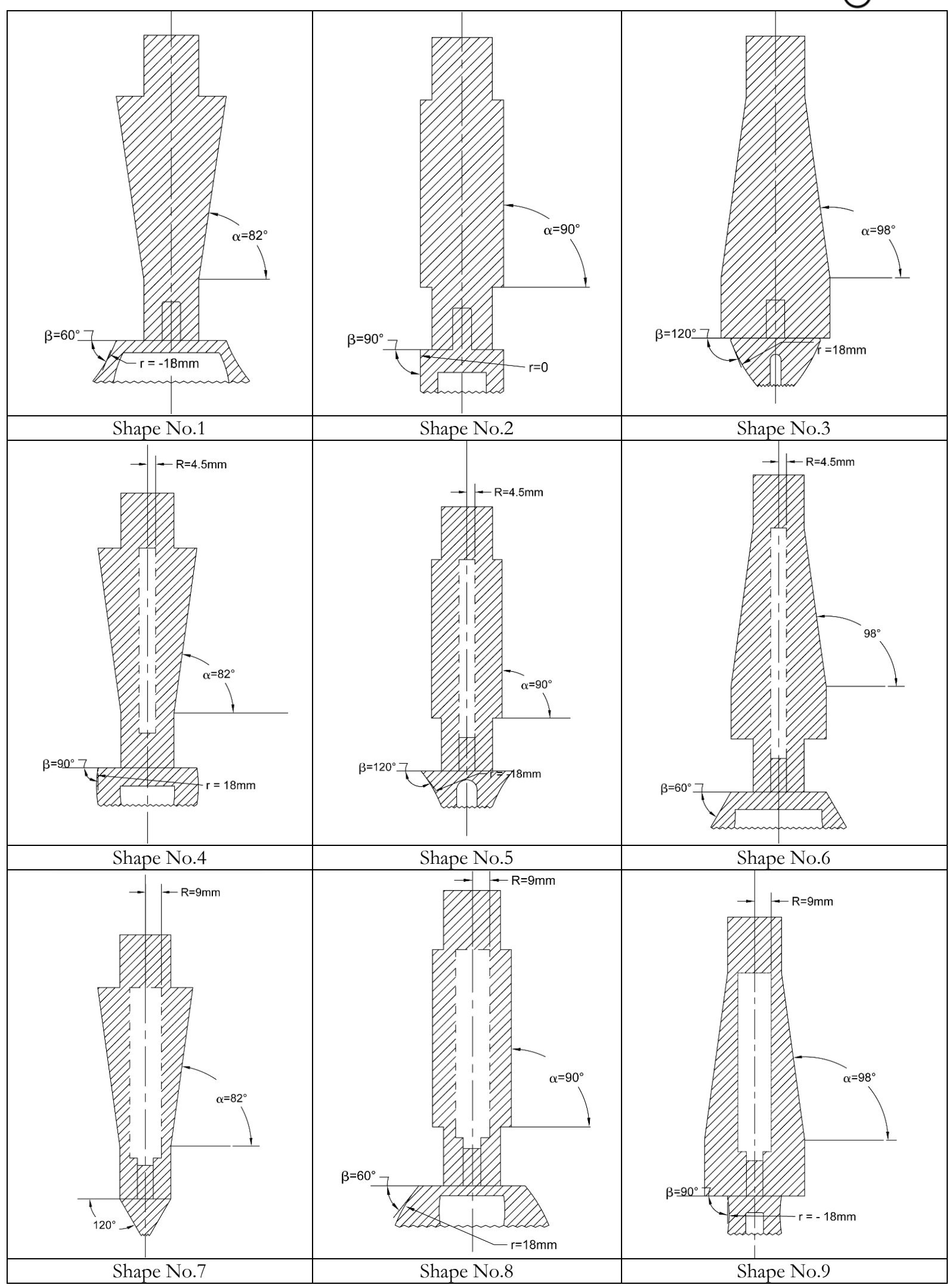




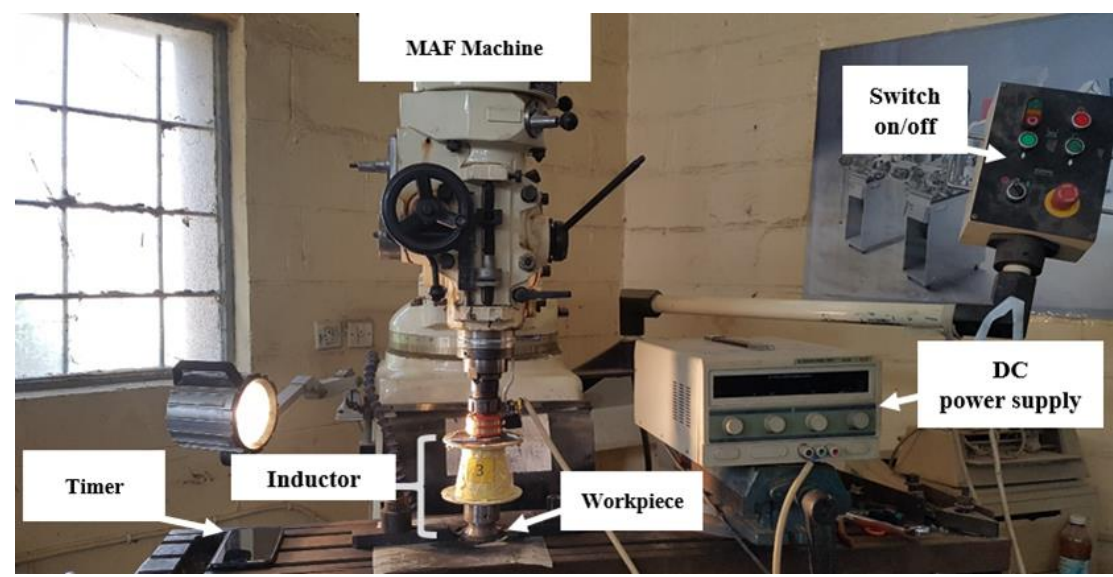

Figure (5): Magnetic abrasive finishing machine.

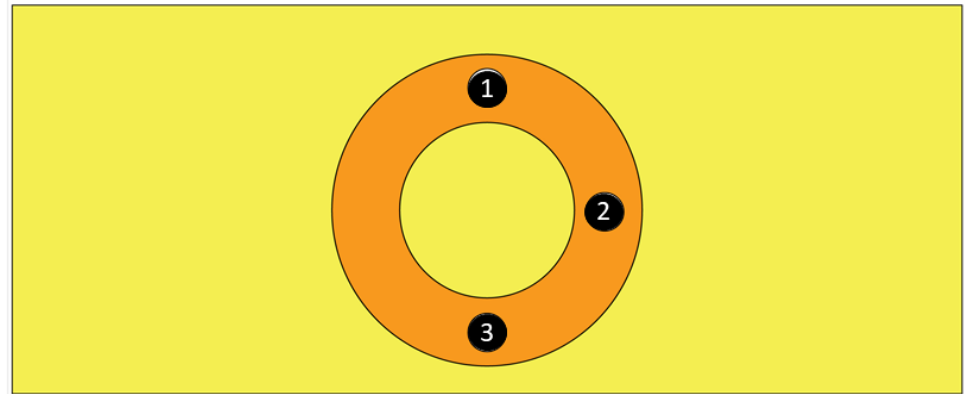

Figure (6): Spots of measured the brass plate

\subsection{Measuring the output parameters of MAF}

The nine workpieces are subjected to two different tests, before MAF and after the MAF method

\subsubsection{Surface Roughness (Ra)}

Surface roughness is measured for 9 experiments by taking three values on the finishing zone, then calculate the average of the three reads. We repeat the measurement procedure before and after the process, for every single workpiece. SRT-6210 was used as a surface roughness measurement tool.

to calculate the change in surface Roughness $(\Delta \mathrm{Ra})$.

$$
\Delta R a=R a_{b e f o r e}-R a_{a f t e r}
$$

\subsubsection{Material removal weight (W):}

The brass plate workpiece weight measured before MAF and after, using the delicate balance for measuring weight. To calculate $\Delta \mathrm{W}$ the change in material removal equation (2) is applied.

$$
\Delta W=W_{\text {before }}-W_{\text {after }}
$$

\section{Results and Discussion}

\subsection{Signal to noise $S / N$ ratio}

The optimal level of each parameter is selected according to the standard (large is better) value of the $\mathrm{S} / \mathrm{N}$ ratio to have a maximum reaction affected the brass workpiece to obtain the refinement of $(\Delta \mathrm{Ra})$ and $(\Delta \mathrm{W})$. The results of mean square diversion (MSD) and signal-to-noise $\mathrm{S} / \mathrm{N}$ ratio are calculated by using MINITAB 18 software [8, 9].

$$
\begin{gathered}
\mathrm{S} / \mathrm{N}=-\log 10\left(\frac{1}{\mathrm{n}} \sum_{\mathrm{i}=1}^{\mathrm{n}}\left(\frac{1}{\mathrm{y}_{\mathrm{i}}^{2}}\right)\right) \\
\mathrm{MSD}=\frac{1}{n} \sum_{i=1}^{n}\left(\frac{1}{y_{\mathrm{i}}^{2}}\right)
\end{gathered}
$$

Where $\mathrm{n}$ number of experiment (input), and $\mathrm{y}_{\mathrm{i}}$ number of measurement (output).

\subsection{Analysis of the surface roughness ( $\Delta R a)$.}

Magnetic abrasive finishing operation were used for enhancing the performance and quality of surface; analyzing the result using $\mathrm{S} / \mathrm{N}$ ratio method to find the optimal level for each experiment by taking the large number for $\mathrm{S} / \mathrm{N}$ ratio. Selected this term according to the standards of Taguchi statistical package in Minitab software. In Minitab software there are three main sets of quality characteristics: "larger is better, nominal is better, smaller is better". In this research, SNR has been chosen according to the criterion (it is better to have larger) to have the maximum reaction. "SNR" and "mean squared deviation (MSD). The mean and $\mathrm{S} / \mathrm{N}$ ratio results and the response for $\Delta \mathrm{Ra}$ are illustrated below in Table 5 and Table $6(\mathrm{a}, \mathrm{b})$, respectively.

Table 5. The Results of the mean and $\mathrm{S} / \mathrm{N}$ ratio of $\Delta \mathrm{Ra}$.

\begin{tabular}{|c|c|c|c|c|c|c|c|}
\hline Experiment & $\begin{array}{c}\text { Radius of } \\
\text { hole } \\
\mathrm{R}(\mathrm{mm})\end{array}$ & $\begin{array}{c}\text { Angle of } \\
\text { core } \alpha \\
\text { (degree) }\end{array}$ & $\begin{array}{c}\text { Angle of } \\
\text { pole } \beta \\
\text { (degree) }\end{array}$ & $\begin{array}{c}\text { Radius } \\
\text { of pole } \\
\mathrm{r}(\mathrm{mm})\end{array}$ & $\Delta \mathrm{Ra}$ & S/N ratio & Mean \\
\hline NUM. & $\boldsymbol{R}$ & $\mathrm{A}$ & $\beta$ & $\mathrm{r}$ & $\Delta \mathrm{Ra}$ & SNRA1 & MEAN1 \\
\hline 1 & 0.0 & 82 & 60 & -18 & 0.12100 & -18.3443 & 0.12100 \\
\hline
\end{tabular}




\begin{tabular}{|c|c|c|c|c|c|c|c|}
\hline 2 & 0.0 & 90 & 90 & 0 & 0.16400 & -15.7031 & 0.16400 \\
\hline 3 & 0.0 & 98 & 120 & 18 & 0.17314 & -15.2321 & 0.17314 \\
\hline 4 & 4.5 & 82 & 90 & 18 & 0.11520 & -18.7710 & 0.11520 \\
\hline 5 & 4.5 & 90 & 120 & -18 & 0.12085 & -18.3551 & 0.12085 \\
\hline 6 & 4.5 & 98 & 60 & 0 & 0.11634 & -18.6854 & 0.11634 \\
\hline 7 & 9.0 & 82 & 120 & 0 & 0.09590 & -20.3636 & 0.09590 \\
\hline 8 & 9.0 & 90 & 60 & 18 & 0.04930 & -26.1431 & 0.04930 \\
\hline 9 & 9.0 & 98 & 90 & -18 & 0.04500 & -26.9357 & 0.04500 \\
\hline Con.test & 0 & 82 & 120 & 0 & & & \\
\hline
\end{tabular}

Table 6.a Response table for signal to noise ratio for $\Delta \mathrm{Ra}$.

Larger is better

\begin{tabular}{|c|c|c|c|c|}
\hline Level & $\mathrm{R}$ & $\alpha$ & $\beta$ & $\mathrm{r}$ \\
\hline 1 & -16.43 & -19.16 & -21.06 & -21.21 \\
\hline 2 & -18.60 & -20.07 & -20.47 & -18.25 \\
\hline 3 & -24.48 & -20.28 & -17.98 & -20.05 \\
\hline Delta & 8.05 & 1.12 & 3.07 & 2.96 \\
\hline Rank & 1 & 4 & 2 & 3 \\
\hline
\end{tabular}

Table 6.b Response table for mean for $\Delta \mathrm{Ra}$.

\begin{tabular}{|c|c|c|c|c|}
\hline Level & $\mathrm{R}$ & $\alpha$ & $\mathrm{B}$ & $\mathrm{r}$ \\
\hline 1 & 0.15271 & 0.11070 & 0.09555 & 0.09562 \\
\hline 2 & 0.11746 & 0.11138 & 0.10807 & 0.12541 \\
\hline
\end{tabular}

\begin{tabular}{|c|c|c|c|c|}
\hline 3 & 0.06340 & 0.11149 & 0.12996 & 0.11255 \\
\hline Delta & 0.08931 & 0.00079 & 0.03442 & 0.02980 \\
\hline Rank & 1 & 4 & 2 & 3 \\
\hline
\end{tabular}

From Table 6.a and $\mathrm{b}$, the value of $\mathrm{S} / \mathrm{N}$ ratio and mean for angle of core $\alpha$ (degree) are not compatible. The main effect plot of $\mathrm{S} / \mathrm{N}$ ratio and mean is shown in Figure 6.a and b. The angle of $\operatorname{core}(\alpha)$ according to the large number is shown in Figure $6(a, b)$ is $98^{\circ}$ and $82^{\circ}$, respectively. Therefore, the prediction should have been done, according to a large number of S/N ratio for the reading that adopted in the present work, as shown in Table 7 . The angle of core $\left(82^{\circ}\right)$.

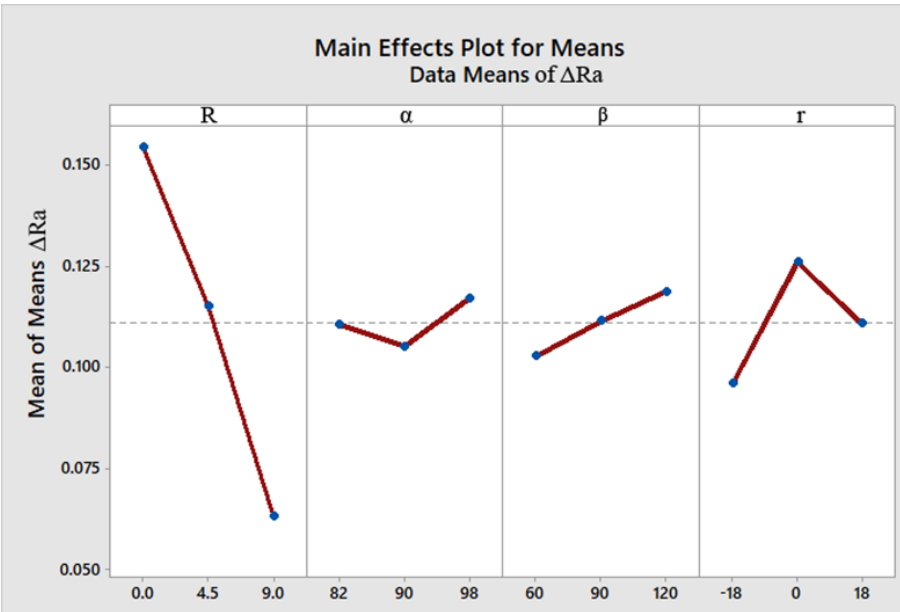

Figure 6.a main effect plot of the mean for $(\Delta \mathrm{Ra})$ with respect to radius of the hole $(\mathrm{R}=\{0,4.5,9\})$, angle of core $(\alpha=\{82,90,98\})$, angle of the pole $(\beta=\{60,90,120\})$, and radius of the pole $(\mathrm{r}=\{-18,0,18\})$.

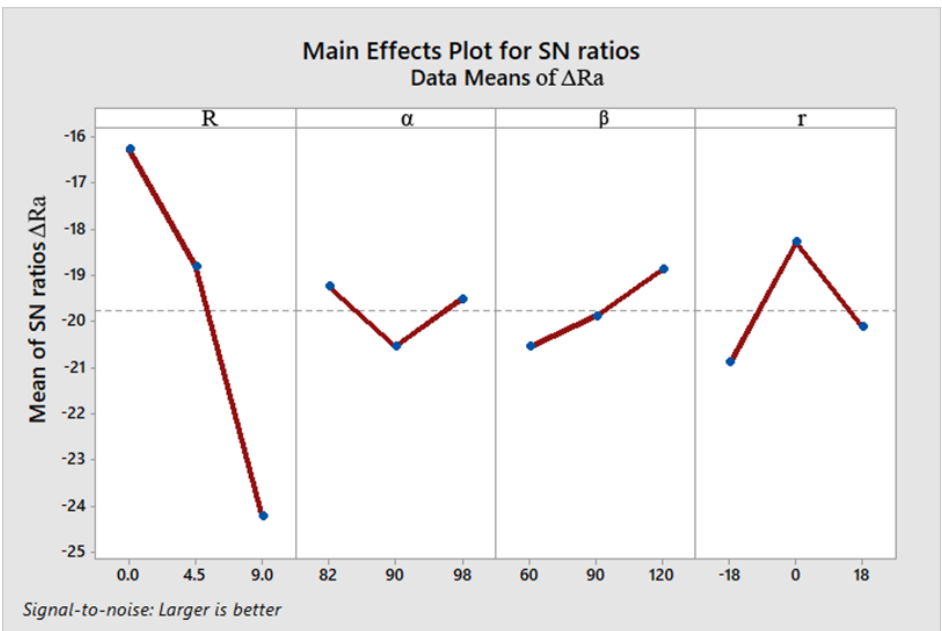

Figure 6.b main effect plot of $\mathrm{S} / \mathrm{N}$ ratio for $(\Delta \mathrm{Ra})$ with respect to radius of the hole $(\mathrm{R}=\{0,4.5,9\})$, angle of core $(\alpha=\{82,90,98\})$, angle of the pole $(\beta=\{60,90,120\})$, and radius of the pole $(r=\{-18,0,18\})$. 
Table 7. The production of the mean and $\mathrm{S} / \mathrm{N}$ ratio of $\Delta \mathrm{Ra}$.

\begin{tabular}{|c|c|c|c|c|c|c|c|}
\hline \multicolumn{4}{|c|}{ Mean } & \multicolumn{4}{|c|}{$\mathrm{S} / \mathrm{N}$ ratio } \\
\hline $\mathrm{R}$ & $\alpha$ & $\beta$ & $\mathrm{r}$ & $\mathrm{R}$ & $\alpha$ & $\beta$ & $\mathrm{r}$ \\
\hline 0 & $98^{\circ}$ & $120^{\circ}$ & 0 & 0 & $82^{\circ}$ & $120^{\circ}$ & 0 \\
\hline \multicolumn{2}{|c|}{ Mean } & \multicolumn{2}{|c|}{$\begin{array}{l}\mathrm{S} / \mathrm{N} \text { ratio } \\
-13.4341\end{array}$} & \multicolumn{2}{|c|}{$\begin{array}{l}\text { Mean } \\
0.185213\end{array}$} & \multicolumn{2}{|c|}{$\begin{array}{l}\mathrm{S} / \mathrm{N} \text { ratio } \\
-12.3093\end{array}$} \\
\hline
\end{tabular}

The best geometry according to the reading adopted in the present work to reach the minimum surface roughness according to the boundary condition of the present research is (radius of hole $\mathrm{R}(0 \mathrm{~mm})$ angle of core $\propto_{1}\left(82^{\circ}\right)$, angle of pole $\beta_{3}\left(120^{\circ}\right)$, radius of pole $r_{2}(0 \mathrm{~mm})$, which is $\left(R_{1}, \alpha_{1}, \beta_{3}, r_{2}\right)$. While the most significant factor that has an effect on $\triangle \mathrm{Ra}$ in MAF process by calculating the difference between the bigger and smaller value of level (Delta) are radius of core $(\mathrm{R})$ followed by angle of pole $(\beta)$, radius of pole (r) lastly, angle of core $(\alpha)$ as shown in

Table 6.a Response table for signal to

\section{noise ratio for $\Delta \mathrm{Ra}$.}

Larger is better

.a and b, which is shown in the line with (Rank). The best design level $\left(R_{1}, \propto_{1}, \beta_{3}, r_{2}\right)$ is not among these nine experiments from scheduled by the orthogonal array. Therefore, $\Delta \mathrm{R}$ a can be determined at the optimum condition $\left(R_{1}, \propto_{1}, \beta_{3}, r_{2}\right)$. The basic dimension of the inductor and pole to reach the minimum of surface roughness are $\left(\Delta \mathrm{Ra}_{o p}\right)$ as shown in Figure 8.

\subsubsection{Analysis of Material removal weight $(\Delta \mathrm{W})$.}

The second criterion that responds to describe the performance and quality of MAF is the $(\Delta \mathrm{W})$, analyzing the result using the same step previously. The result of mean and $\mathrm{S} / \mathrm{N}$ ratio as shown in Table 8. and the response table for both mean and $\mathrm{S} / \mathrm{N}$ ratio are shown in Table 9.a and b.

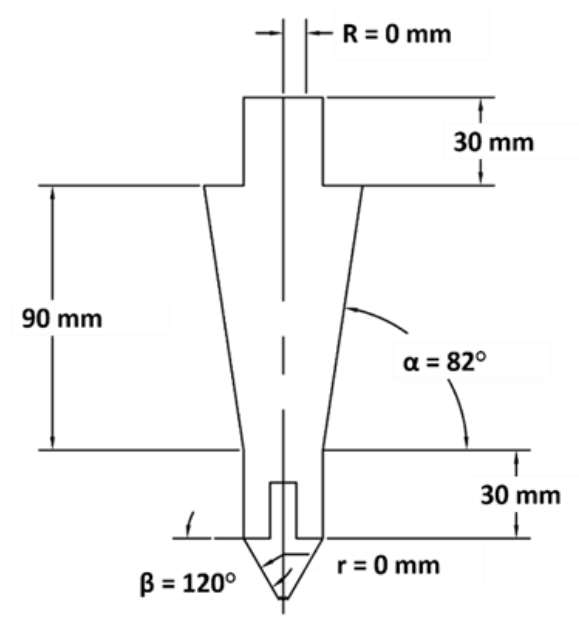

Figure (8): The optimum geometry dimension of the core and pole for the optimum shape $\left(\Delta \mathrm{Ra}_{o p}\right)$, depending on values of parameters that adopted in the present work.

Table (8): The Results of the mean and $\mathrm{S} / \mathrm{N}$ ratio of $\Delta \mathrm{W}$.

\begin{tabular}{|c|c|c|c|c|c|c|c|}
\hline Experiment & $\begin{array}{c}\text { The Radius of } \\
\text { the hole } \\
\mathrm{R}(\mathrm{mm})\end{array}$ & $\begin{array}{c}\text { The Angle of } \\
\text { a core } \\
\alpha \text { (degree) }\end{array}$ & $\begin{array}{c}\text { The Angle of } \\
\text { the pole } \\
\beta \text { (degree) }\end{array}$ & $\begin{array}{c}\text { The Radius of } \\
\text { a pole } \\
\mathrm{r}(\mathrm{mm})\end{array}$ & $\begin{array}{c}\text { Change in } \\
\text { material } \\
\text { removal }\end{array}$ & S/N ratio & Mean \\
\hline NUM. & $\boldsymbol{R}$ & $\alpha$ & $\beta$ & $\mathrm{r}$ & $\Delta \mathrm{W}$ & SNRA3 & MEAN3 \\
\hline 1 & 0.0 & 82 & 60 & -18 & 0.0199100 & -34.0186 & 0.0199100 \\
\hline 2 & 0.0 & 90 & 90 & 0 & 0.0189650 & -34.4409 & 0.0189650 \\
\hline 3 & 0.0 & 98 & 120 & 18 & 0.0105600 & -39.5267 & 0.0105600 \\
\hline 4 & 4.5 & 82 & 90 & 18 & 0.0223100 & -33.0300 & 0.0223100 \\
\hline 5 & 4.5 & 90 & 120 & -18 & 0.0051040 & -45.8418 & 0.0051040 \\
\hline 6 & 4.5 & 98 & 60 & 0 & 0.0069160 & -43.2029 & 0.0069160 \\
\hline 7 & 9.0 & 82 & 120 & 0 & 0.0101830 & -39.8425 & 0.0101830 \\
\hline 8 & 9.0 & 90 & 60 & 18 & 0.0110800 & -39.1092 & 0.0110800 \\
\hline 9 & 9.0 & 98 & 90 & -18 & 0.0015500 & -56.1934 & 0.0015500 \\
\hline Con.test & 0 & 82 & 60 & 18 & & & \\
\hline
\end{tabular}


Table 9.a :response table for signal to noise ratio

\begin{tabular}{|c|c|c|c|c|}
\hline Level & R & $\alpha$ & B & r \\
\hline 1 & -36.00 & -35.63 & -38.78 & -45.35 \\
\hline 2 & -40.69 & -39.80 & -41.22 & -39.16 \\
\hline 3 & -45.05 & -46.31 & -41.74 & -37.22 \\
\hline Delta & 9.05 & 10.68 & 2.96 & 8.13 \\
\hline Rank & 2 & 1 & 4 & 3 \\
\hline
\end{tabular}

Table 9.b: response table for mean for $\Delta \mathrm{W}$.

$$
\text { Larger is better }
$$

\begin{tabular}{|c|c|c|c|c|}
\hline Level & $\mathrm{R}$ & $\alpha$ & $\mathrm{B}$ & $\mathrm{r}$ \\
\hline 1 & 0.016478 & 0.017468 & 0.012635 & 0.008855 \\
\hline 2 & 0.011443 & 0.011716 & 0.014275 & 0.012021 \\
\hline 3 & 0.007604 & 0.006342 & 0.008616 & 0.014650 \\
\hline Delta & 0.008874 & 0.011126 & 0.005659 & 0.005795 \\
\hline Rank & 2 & 1 & 4 & 3 \\
\hline
\end{tabular}

From Table 9. a and $\mathrm{b}$ (angle of pole $\beta$ ) for both mean and $\mathrm{S} / \mathrm{N}$ ratio are not matched according to the largest number of $\mathrm{S} / \mathrm{N}$ ratio (large is better), as shown in Table 10. The main effect plot of $\mathrm{S} / \mathrm{N}$ ratio and mean is shown in Figure 9(a,b). The angle of pole $(\beta)$ according to the large number in Figure $9 . \mathrm{a}$ and $\mathrm{b}$ is $90^{\circ}$ and $60^{\circ}$, respectively. Therefore, the prediction must be adopted for solving that mismatch.

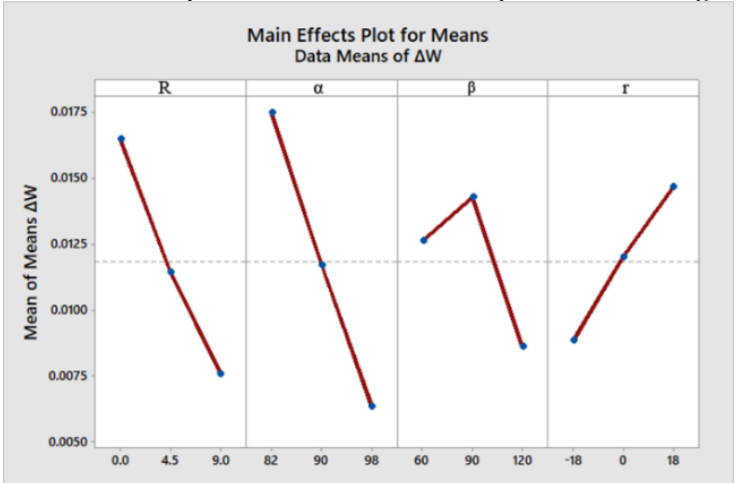

Figure 9.a main effect plot of Mean for $(\Delta \mathrm{W})$ with respect to radius of the hole $(\mathrm{R}=\{0,4.5,9\})$, angle of core $(\alpha=\{82,90,98\})$, angle of the $\operatorname{pole}(\beta=$

$\{60,90,120\})$, and radius of the pole $(\mathrm{r}=$ $\{-18,0,18\})$.

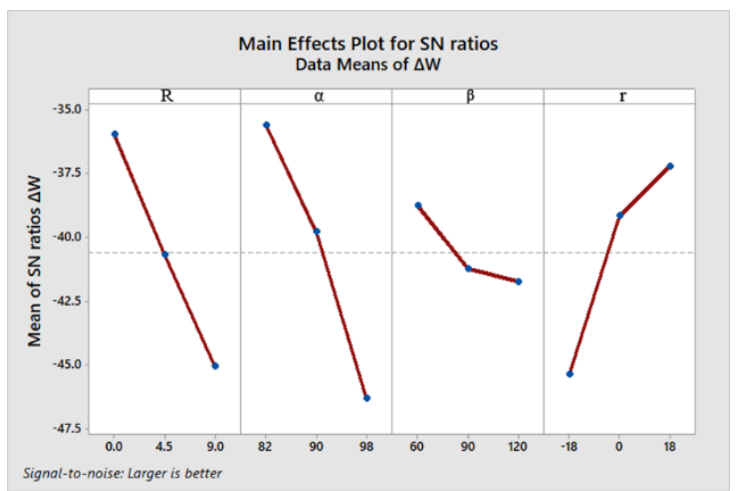

Figure 9.b main effect plot of $\mathrm{S} / \mathrm{N}$ ratio for $(\Delta \mathrm{W})$ with respect to radius of the hole $(\mathrm{R}=\{0,4.5,9\})$, angle of core $(\alpha=\{82,90,98\})$, angle of the pole $(\beta=$

$\{60,90,120\})$, and radius of the pole $(\mathrm{r}=$

$$
\{-18,0,18\}) \text {. }
$$

Based on the higher number of signals to noise ratio (-25.8893) in Error! Reference source not found., the optimal number is found at (raduis of hole R $(0 \mathrm{~mm})$, angle of core $\alpha_{1}\left(82^{\circ}\right)$, angle of pole $\beta_{1}\left(60^{\circ}\right)$, and radius of pole $r_{3}(18 \mathrm{~mm})$. Therefore, the optimum level is $\left(R_{1}, \propto_{1}, \beta_{1}, r_{3}\right)$ for optimum $(\Delta W)$. In the same way, according to the line of (Rank) shown in 
Table 9.a :response table for signal to noise ratio for $\Delta \mathrm{W}$.

(a,b), the value of these optimum levels is not found among the nine experiments. Therefore, $(\Delta \mathrm{W})$

- The basic dimension and fabrication of the inductor and pole to reach the optimum of material removal rate $\left(\Delta \mathrm{W}_{O P}\right)$.as shown in Figure 10 .

\subsection{ANOVA Technique}

\subsubsection{ANOVA Technique for $(\Delta \mathrm{Ra})$}

Analysis of variance (ANOVA) test is a statistical processing which is used for determining the $\mathrm{P} \%$ (percentage of contribution) for each parameter (radius of the hole, angle of the core, angle of the pole, the radius of a pole). ANOVA has been applied for the first criteria $(\triangle \mathrm{Ra})$ as shown in Table 11.

It can be noticed according to Table 11, that the large parameter effect on surface roughness is the radius of hole followed by the angle of pole followed by the radius of a pole which means that these parameters have a large effect on surface roughness compared to the angle of the core. The regression model for surface roughness has been obtained below

$$
\Delta R a=0.0998-0.00992 R+0.000050 \alpha
$$

$$
+0.000574 \beta+0.000470 r
$$

MINITAB18 is used to find R-seq value that is clearly assigned the effectiveness of method.

$$
\mathrm{R} \text {-sq }=91.38 \%
$$

\subsubsection{ANOVA Technique for $(\Delta \mathrm{W})$}

Using the same way that used previously, ANOVA is performed on the second criterion (material removal rate $\Delta \mathrm{W}$ ). It has found that the angle of the core is the is evaluated at these optimum condition values $\left(R_{1}, \propto_{1}, \beta_{1}, r_{3}\right)$ and is also not found among these nine experiments that are shown in

parameter with the highest impact on the $\Delta \mathrm{W}$ followed by the radius of the hole, followed by the radius of a pole. While the angle of the pole shows the lowest impact on $\Delta \mathrm{W}$. as shown in Table 12.

The regression model for material removal rate has been obtained below

$$
\begin{array}{r}
\Delta W=0.0849-0.000986 R-0.000695 \alpha \\
-0.000067 \beta+0.000161 r
\end{array}
$$

$\mathrm{R}$-sq $=93.21 \%$

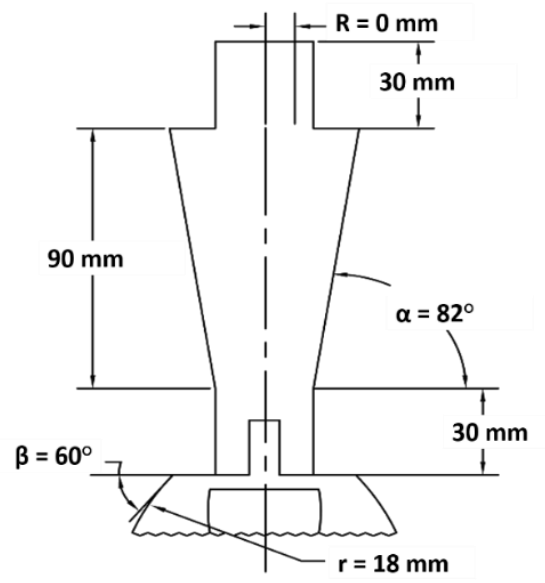

Figure (10): The optimum geometry dimensions for the inductor and pole for the optimum shape $\left(\Delta \mathrm{W}_{O P}\right)$. depending on values of parameters that adopted in the present work

Table (10): Analysis of variance (ANOVA) for surface roughness

\begin{tabular}{|c|l|l|l|l|l|l|l|l|}
\hline Source & DF & Adj SS & Adj MS & F-Value & P-Value & & \multicolumn{2}{l|}{$\begin{array}{l}\text { Contribution } \\
\text { test }\end{array}$} \\
\hline Regression & 4 & 0.014173 & 0.003543 & 12.53 & 0.016 & & & $(1)$ \\
\hline R & 1 & 0.011965 & 0.011965 & 42.31 & 0.003 & Significant & 84.42108 & $(4)$ \\
\hline A & 1 & 0.000001 & 0.000001 & 0.00 & 0.957 & Not- Significant & 0.007056 & $(2)$ \\
\hline B & 1 & 0.001777 & 0.001777 & 6.28 & 0.066 & Not- Significant & 12.53792 & $(3)$ \\
\hline R & 1 & 0.000430 & 0.000430 & 1.52 & 0.285 & Not- Significant & 3.033938 & $(3)$ \\
\hline Error & 4 & 0.001131 & 0.000283 & & & & & \\
\hline Total & 8 & 0.015304 & & & & & & \\
\hline
\end{tabular}

Table (11): Analysis of variance (ANOVA) for material removal.

\begin{tabular}{|c|l|l|l|l|l|l|l|l|}
\hline Source & DF & Adj SS & Adj MS & F-Value & P-Value & & & \multirow{2}{*}{ Contribution value $\%$} \\
\hline Regression & 4 & 0.000378 & 0.000095 & 13.73 & 0.013 & & & \\
\hline R & 1 & 0.000118 & 0.000118 & 17.14 & 0.014 & Significant & 31.21693 & $(2)$ \\
\hline A & 1 & 0.000186 & 0.000186 & 26.94 & 0.007 & Significant & 49.20635 & $(1)$ \\
\hline B & 1 & 0.000024 & 0.000024 & 3.52 & 0.134 & Not- Significant & 6.349206 & $(4)$ \\
\hline R & 1 & 0.000050 & 0.000050 & 7.31 & 0.054 & Significant & 13.22751 & $(3)$ \\
\hline Error & 4 & 0.000028 & 0.000007 & & & & & \\
\hline Total & 8 & 0.000406 & & & & & & \\
\hline
\end{tabular}

\section{Conclusions}

According to the achieved results in this work, the following conclusions have been obtained.

(1) Successful implementation and design of magnetic inductor and pole that used for flat surfaces such as brass workpiece.
(2) The most significant factor that affects the change in surface roughness $(\Delta \mathrm{R})$ is the radius of hole $\mathrm{R}$ by $(84 \%)$.

(3) The optimal parameter for achieving minimum surface roughness are radius of hole $\mathrm{R}(0 \mathrm{~mm})$, angle of 
core $\alpha_{1}\left(82^{\circ}\right)$, angle of pole $\beta_{3}\left(120^{\circ}\right)$, radius of pole $\mathrm{r}_{2}(0 \mathrm{~mm})$, which is $\left(\mathrm{R}_{1}, \propto_{1}, \beta_{3}, \mathrm{r}_{2}\right)$.

(4) The change in material removal weight $(\Delta \mathrm{W})$ has many factors that have a significant effect on it is the angle of core $\alpha$ by (49\%) following by radius of hole $\mathrm{R}$ by $(31 \%)$ and the radius of the pole by $(13 \%)$.

(5) The optimum parameters that give larger change in $(\Delta \mathrm{W})$ are radius of hole $R_{1}(0 \mathrm{~mm})$, angle of core $\alpha_{1}$ $\left(82^{\circ}\right)$, angle of pole $\beta_{1}\left(60^{\circ}\right)$ and radius of pole $r_{3}(18 \mathrm{~mm})$, which is $\left(R_{1}, \propto_{1}, \beta_{1}, r_{3}\right)$.

\section{References}

[1] V. Jain, Advanced machining processes. 2009.

[2] D. Hayes and D. Wolford, "Art of reducing magnetostrictive effects in magnetic materials," Pat. Trademark

Off., no. U.S. Patent No 2,234,968, 1941.

[3] R. K. Jain and V. K. Jain, "Abrasive Fine Finishing Processes," J. Manuf. Sci. Prod., vol. 2, no. 1, pp. 55-68, 2011.

[4] A. a Moosa, "Utilizing a Magnetic Abrasive Finishing Technique ( MAF ) Via Adaptive Nero Fuzzy ( ANFIS )," Am. J. Mater. Eng. Technol., vol. 1, no. 3, pp. 49-53, 2013.

[5] M. G. Patil, K. Chandra, and P. S. Misra, "Magnetic abrasive finishing - A review," Adv. Mater. Res., vol. 418-420, pp. 1577-1581, 2012.

[6] L. D. Yang, C. T. Lin, and H. M. Chow, "Optimization in MAF operations using Taguchi parameter design for AISI304 stainless steel," Int. J. Adv. Manuf. Technol., vol. 42, no. 5-6, pp. 595605, May 2009.

[7] B. Deepak, R. Walia, N. S.-I. J. S. E. M. Technol, and U. 2012, "Effect of rotational motion on the flat work piece magnetic abrasive finishing," vol. 2, pp. 50-54, 2012.

[8] H. Yamaguchi, A. Srivastava, ... M. T.-C. J. of, and U. 2014, "Magnetic Abrasive Finishing of cutting tools for high-speed machining of titanium alloys," Elsevier, vol. 7, no. 4, pp. 299-304, 2014.

[9] S. M. Mousa, "Optimization the Parameters of Magnetic Abrasive Process Using Taguchi Method to Improve the Surface Roughness," AlKhwarizmi Eng. J., vol. 13, no. 2, pp. 11-19, 2017.

[10] A. Chaurasia and V. Wankhede, "Magnetic Abrasive Finishing of Inconel 718 Super Alloy Using Permanent Magnet Ankur,” Int. Res. J. Eng. Technol., vol. 05, no. 05, pp. 1165-1168, 2018.

[11] Y. Tian, C. Shi, Z. Fan, and Q. Zhou, "Experimental investigations on magnetic abrasive finishing of Ti-6Al-4V using a multiple pole-tip finishing tool," Int. J. Adv. Manuf. Technol., vol. 106, no. 7-8, pp. 3071-3080, 2020.

[12] P. Munyensanga, P. Paryanto, and M. N. A. Aziz, "Application of Polishing AISI 316L Stainless Steel Ball Bearing with A Magnetic Abrasive Finishing Process: A Review," Rotasi, vol. 20, no. 4, p. 249, 2019.

[13] P. Singh, L. Singh, and A. Kaushik, "Parametric optimization of magnetic abrasive finishing using adhesive magnetic abrasive particles," Int. J. Surf. Eng. Interdiscip. Mater. Sci., vol. 7, no. 2, pp. 3447, 2019.
[14] Y. M. Baron, S. L. Ko, and J. I. Park, "Characterization of the magnetic abrasive finishing method and its application to deburring," Key Eng. Mater., vol. 291-292, pp. 291-296, 2005.

[15] F. F. Mustafa, A. H. Kadhym, and H. H. Yahya, "Tool geometries optimization for friction stir welding of AA6061-T6 aluminum alloy T-joint using taguchi method to improve the mechanical behavior," J. Manuf. Sci. Eng. Trans. ASME, vol. 137, no. 3, pp. 1-8, 2015.

[16] D. K. Singh, V. K. Jain, and V. Raghuram, "Parametric study of magnetic abrasive finishing process," J. Mater. Process. Technol., vol. 149, no. 1-3, pp. 22-29, 2004. 